\title{
The Study of WeChat Payment Users Willingness Factor
}

\author{
Wei Xu \\ College of Business Administration, University of Science and Technology Liaoning, Anshan, China \\ Email: xuweishally@163.com
}

How to cite this paper: $\mathrm{Xu}, \mathrm{W}$. (2017) The Study of WeChat Payment Users Willingness Factor. Journal of Service Science and Management, 10, 251-259.

https://doi.org/10.4236/jssm.2017.103021

Received: April 25, 2017

Accepted: June 9, 2017

Published: June 12, 2017

Copyright $\odot 2017$ by author and Scientific Research Publishing Inc. This work is licensed under the Creative Commons Attribution International License (CC BY 4.0).

http://creativecommons.org/licenses/by/4.0/

\begin{abstract}
Based on the user's perceived value and perceived risk, this paper constructs the model of the willingness to use the willingness to pay the user, designs the corresponding questionnaire and conducts the online sample survey, and uses Excel and SPSS20.0 to analyze the theoretical model and research hypothesis, then puts forward some suggestions to promote the development of WeChat payment platform, hoping to provide a reference for the development of WeChat payment.
\end{abstract}

\section{Keywords}

WeChat Payment, Using Intention, Perceived Value, Perceived Risk, Mobile Payment

\section{Introduction}

\subsection{Introduction and Status of WeChat Payment}

WeChat payment is the mobile payment innovation product jointly launched by Tencent's well-known mobile social communications software-WeChat and third-party payment platform-TenPay. Before the payment, you need to bind a bank card in the micro letter, fill in the bank card number, bank card type, cardholder's name, cardholder's ID number, mobile phone number, mobile phone verification code to complete the identity authentication. After you can buy business partners and services, payment only needed to enter the password can simply complete the transaction. Up to now, WeChat payment has launched four payment methods, namely Public number payment, APP payment, Sweep payment, Credit card payment. WeChat payment is an important platform for mobile payment, with convenience, flexibility, low cost characteristics for the majority of users to meet the various needs.

On the one hand, in recent years, with the help of the world's largest social 
platform-WeChat, there are more than 100 million bank accounts in the WeChat payment or QQ wallet binding. Combined with the trickle and WeChat red envelopes driven by WeChat to pay the user base of rapid growth, it not only made more people understand the mobile payment, but also opened up a new form of payment based on social platform. In the past two years, WeChat payment actively sought cooperation; in SF Express, Jingdong's pat network, Shenzhou car and Carrefour, a WeChat payment interface was opened; WeChat payment continue to expand the online mobile payment scene, continue to provide consumers with simple shopping experience.

However, changes in the mobile payment market last year showed that WeChat red envelopes did not give a breakthrough in the field of mobile payment. WeChat payment is facing the biggest problem; it is precisely the user's retention and conversion rate. The user's retention rate is the users in a certain period of time to start using the application, after a period of time, still continue to use the application; this part of users were accounted for the proportion of new users whose retention rate will be in accordance with every 1 unit time Day, week, month).The user's conversion rate means to potential users or target customers into the customer ratio through advertising and marketing [1]. Because the payment is the need for the scene, and this is precisely the biggest weakness of the WeChat. According to incomplete statistics, WeChat payment function limited to a taxi, red envelopes, payment, etc., pay the scene compared with Alipay is not a small gap, in order to move on the road to go farther, but also to expand payment Scenes.

\subsection{Definition of Consumer Value Behavior Theory}

\subsubsection{Perceived Value Theory}

People pay more attention to the value of the product and the expectations of the product. Consumers in the course of the transaction hope to achieve a certain perceived value. WeChat payment as a social and mobile payment integration platform, in the payment process will inevitably make consumers in the perception of profit and perceived gains and losses in a proportion, and ultimately the formation of perceived value. The profitability of WeChat payment can include: saving customer time, providing life service business (mobile phone recharge, living payment, transfer, donation, etc.), financial investment, which greatly facilitate the consumer's life; perceived loss mainly include: Mobile phone costs, mobile phone traffic, mobile phone calls, to understand the time and cost of WeChat payment processes and methods, so if people in the use of WeChat payment process, to get more revenue, will be more favored for WeChat payment [2].

\subsubsection{Perceived Risk Theory}

Perceived risk that is, the consumer cannot predict whether the results meet the expected target at the time of purchase, the uncertainty of this result is the initial concept of perceived risk, this uncertainty mainly includes two aspects, one is uncertain to buy Whether the results meet the purchase purpose, the second is 
the wrong decision to lead to the severity of the consequences of uncertainty, that is, consumers fear the loss is too large, do not know what kind of risk will face. With the development of e-commerce, perceived risk also increased from the first five factors to seven factors, namely, time risk, privacy risk, functional risk, financial risk, psychological risk, physical risk and social risk [3].

WeChat payment is integrated micro-client, platform-based data and transmission, payment process without face-to-face payment process. WeChat payment is still in a new field, whether it is publicity or follow-up services are not perfect, its function for some people are also unfamiliar; consumers because of WeChat payment technology security do not understand, so there will be psychological concerns; WeChat payment not only a simple payment process, which involves the user's name, identity card, bank number, or even address and other privacy information, if the information is unhealthy business leak or loss of mobile phone users will cause huge losses, so the user information security for WeChat payment is a great test.

\subsection{The Paper's Study Significance}

WeChat payment as a mobile payment field rookie, but how to tap the "dead" users and potential users and increase the viscosity of existing users are now the primary goal, therefore, to explore the factors that affect the user's use of WeChat payment is particularly important.

This paper mainly solves the following problems, first of all, analyzes the factors that affect the willingness of users to pay for the use of WeChat; Second, the analysis of the impact of the use of users and WeChat payment direction; Third, the analysis of different age groups, The degree of acceptance and use of WeChat payment of the influencing factors; Fourth, from the theory to the model, analysis of WeChat payment in the marketing process need to control the factors.

\section{Definition of Research Hypothesis}

\subsection{Perceived Earnings (H1: Positive Impact on WeChat Payment User's Willingness to Use)}

Perceived benefits include direct income and indirect benefits, the so-called direct income refers to the benefits of money, such as saving fees and service fees. Indirect benefit is that consumers in the use of WeChat payment, make life, entertainment, shopping, financial management, work and other activities become efficient and fast. It can be seen that high perceived benefits will make consumers more willing to accept WeChat payments [4].

\subsection{Security Risks \\ (H2: WeChat to Pay Users to Use a Negative Impact)}

Raymond Bauer (1960) argues that perceived risk is the consumer's perceived uncertainty about the outcome of his buying behavior. Users are often aware of the risk of WeChat will be threatened to bind the bank card property security, WeChat account leak or loss of mobile phone will let the WeChat to pay privacy 
disclosure, or fear of payment during the network instability caused by property damage The perception of a security risk can have a negative impact on the willingness to use.

\subsection{Group Impact}

(H3: WeChat to Pay Users to Use a Positive Impact)

Ajzen's theory of rational behavior suggests that subjective norms are internal factors that affect individual behavior, and subjective norms are the pressures of social customs and groups when individuals make decisions about an action. Even if the user does not know the WeChat paid or did not expect to use WeChat payment, but they will be affected by the use of people around to understand and accept WeChat payment model [5].

\subsection{Marketing Promotion \\ (H4: WeChat to Pay Users to Use a Positive Impact)}

Marketing promotion as a medium of communication between merchants and consumers, products, services, images, brands, etc., are disseminated to consumers to understand and accept. The factors that influence consumer behavior decision-making include their own awareness of the product and the external environment, the external environment not only from the community groups, as well as business marketing promotion. WeChat marketing promotion can be described as a hit, with WeChat red envelopes and taxi software, WeChat payment quickly came to millions of households, a good marketing program can help enterprises get more benefits.

\subsection{Product Innovation}

\section{(H5: WeChat to Pay Users to Use a Positive Impact)}

As a new generation of new technology and new things have a strong interest, they dare to contact new things and good at trying, so WeChat should be innovative as a fundamental $\mathrm{R} \& \mathrm{D}$, a good new research and development will inevitably attract a large number of users.

\section{Designing of the User Willingness Questionnaire Based on the WeChat Payment}

\subsection{The Content Design of the User Willingness}

See Table 1.

\subsection{Questionnaire Design}

This paper aims to study the impact of WeChat users to use the willingness to use factors, through the questionnaire to collect the required data information.

(1) Questionnaire structure

The content of the questionnaire is divided into three parts, the first part is the user's personal information, including gender, age, occupation, monthly dis- 
Table 1. Measurement variables for study variables.

\begin{tabular}{|c|c|}
\hline \multirow{3}{*}{$\begin{array}{c}\text { Perceived } \\
\text { benefits }\end{array}$} & $\begin{array}{l}\text { If the WeChat payment allows me to buy products or } \\
\text { services more convenient, easy, I will use }\end{array}$ \\
\hline & $\begin{array}{l}\text { If the WeChat payment provided by the financial products } \\
\text { can make me get a good return on investment, I will use }\end{array}$ \\
\hline & $\begin{array}{l}\text { If the WeChat payment can get me to get } \\
\text { extra discounts and benefits, I will use it }\end{array}$ \\
\hline \multirow{6}{*}{ Security risk } & Use inconvenience to avoid carrying cash and bank cards, I will use \\
\hline & $\begin{array}{l}\text { If the WeChat payment in the provision of personal } \\
\text { privacy information is safe, I will use }\end{array}$ \\
\hline & If the WeChat payment is safe at the time of payment, I will use it \\
\hline & If the use of WeChat payment process, \\
\hline & the account information will not be lost, I will use \\
\hline & If the WeChat payment security issues, I will not use \\
\hline \multirow{4}{*}{$\begin{array}{l}\text { The group } \\
\text { affects }\end{array}$} & my friends in the use of WeChat to pay, I also want to use \\
\hline & Micro letter payment is too popular, I want to use \\
\hline & $\begin{array}{l}\text { When using microseconds to pay, people around } \\
\text { will think I am more fashionable and I will use }\end{array}$ \\
\hline & $\begin{array}{l}\text { I will pay for the use of WeChat because someone } \\
\text { else's choice of WeChat payment }\end{array}$ \\
\hline \multirow{4}{*}{$\begin{array}{l}\text { Marketing } \\
\text { Promotion }\end{array}$} & $\begin{array}{l}\text { marketing businesses will increase the number of } \\
\text { marketing activities I use WeChat to pay the probability }\end{array}$ \\
\hline & Media, advertising will improve my use of WeChat to pay the possibility \\
\hline & The more I pay for the micropayment, the more I will use it \\
\hline & I like business to engage in some promotional activities \\
\hline \multirow{4}{*}{$\begin{array}{l}\text { Product } \\
\text { innovation }\end{array}$} & WeChat payment release new features when I will use \\
\hline & WeChat payment and Alipay use feel different when I will use \\
\hline & I hope that WeChat payment is not only paid function \\
\hline & I like to try new products and new services \\
\hline \multirow{2}{*}{ Use intention } & I intend to use or continue to use the micro letter to pay \\
\hline & I will recommend to friends around the WeChat to pay \\
\hline
\end{tabular}

posable income and education level. The second part is the use of WeChat payment survey, the use of life, frequency, use and the maximum amount of one-time transaction to ask questions, if not, then do not use the reasons for questioning. The third part is the design of the scale for the variables, including the use of scenarios, perceived ease of use, perceived usefulness, etc., using Liker 5 scale measurement [6].

(2) Questionnaire before the test

In this paper, the questionnaires were collected from Liaoning University of Science and Technology, and the questionnaires were collected by way of on-site distribution. 26 questionnaires were received and 21 valid questionnaires were received. The data collected in the pre-test process are collated and analyzed, and it is found that the variables are well coordinated, and the internal consis- 
tency coefficient is required. There is no need to delete the items. Finally, in order to avoid the problem of incorrect terminology in the questionnaire, semantic unknown, invited experienced students and professional teachers to answer the questionnaire and make recommendations to form a formal questionnaire.

\subsection{Questionnaires Issued and Recovered}

The survey was conducted by means of random sampling. The survey was mainly conducted by network research and paper questionnaires. The survey subjects were mainly college students and office workers, and 156 questionnaires were finally collected. 28 valid questionnaires were sorted out and valid questionnaires were obtained. Effective recovery rate of $82 \%$.

\section{WeChat Payment under the User's Willingness to Use Quantitative Analysis}

Based on the analysis of the sample data collected by Excel, the reliability analysis and structural equation model validation of the data were carried out by using SPSS20.0 software, and the hypothesis was established according to the result of the analysis.

\subsection{Descriptive Analysis}

\subsubsection{Sample Population Basic Information Statistics}

Because the survey object for college students and young office workers, the main features of the volume presents a young, high academic qualifications, the monthly disposable income characteristics.

\subsubsection{Sample Population Using WeChat Payment Statistics}

From the Table 2 can be seen, the majority of people in the sample population to use the monthly payment of 1 - 5 letters, the proportion of the total number of $63.3 \%$; acceptable one-time maximum turnover of $50-200$ yuan, followed by 200 - 500 yuan, The two accounted for $82.6 \%$ of the total sample; the use of WeChat in the sample is the main use of shopping consumption, followed by life contributions. More than the above, the sample population using WeChat payment frequency is low. Acceptable one-time maximum transaction amount is also low and may be affected by monthly disposable income. Sample population mainly through WeChat to pay for shopping, online shopping to a certain extent, promote the development of WeChat payment.

\subsection{Regression Analysis}

Let us assume that the regression model is

$$
Y=a+b X_{1}+c X_{2}+d X_{3}+e X_{4}+f X_{5}
$$

where $X_{1}$ is the perceived benefit, $X_{2}$ is the security risk, $X_{3}$ is the group influence, $X_{4}$ is the marketing Promotion, $X_{5}$ for the product innovation, a constant, $b, c, d, e$ and $f$ is the independent variable coefficient. The regression coefficients and the significance coefficients are shown in Table 3. 
Table 2. Statistics on the use of WeChat payment in the sample population $(n=128)$.

\begin{tabular}{cccc}
\hline $\begin{array}{c}\text { Sample statistical } \\
\text { characteristics }\end{array}$ & classification & $\begin{array}{c}\text { The number } \\
\text { of people }\end{array}$ & $\begin{array}{c}\text { The proportion } \\
\text { of the total number }\end{array}$ \\
\hline $\begin{array}{c}\text { Monthly usage } \\
\text { (Time) }\end{array}$ & Not used & 9 & $7.0 \%$ \\
& $1-5$ & 81 & $63.3 \%$ \\
Acceptable one-time & $>5$ & 38 & $19.7 \%$ \\
maximum transaction & 50 - 200 & 4 & $3.1 \%$ \\
amount (yuan) & $200-500$ & 70 & $54.5 \%$ \\
& $5000-1000$ & 36 & $28.1 \%$ \\
& $>1000$ & 15 & $11.7 \%$ \\
& Shopping consumption & 82 & $2.6 \%$ \\
Mainly used business type & Life payment & 45 & $64.1 \%$ \\
(multiple choice) & Investment and & 31 & $35.2 \%$ \\
& financial management & 63 & $24.2 \%$ \\
& Life entertainment & 27 & 49.2 \\
& Transfer, repayment & & $21.1 \%$ \\
\hline
\end{tabular}

Table 3. Regression analysis coefficient and significant coefficient results table.

\begin{tabular}{|c|c|c|c|c|c|c|}
\hline & \multirow{2}{*}{ model } & \multicolumn{2}{|c|}{$\begin{array}{c}\text { Non-normalized } \\
\text { coefficients }\end{array}$} & \multirow{2}{*}{$\begin{array}{c}\begin{array}{c}\text { Normalization } \\
\text { coefficient }\end{array} \\
\text { trial version }\end{array}$} & \multirow[t]{2}{*}{$\mathrm{T}$} & \multirow[t]{2}{*}{ Sig } \\
\hline & & B & Standard error & & & \\
\hline \multirow{6}{*}{$\begin{array}{l}\text { User use } \\
\text { intention } \\
\text { model }\end{array}$} & constant & 3.802 & 0.045 & - & 84.426 & 0.000 \\
\hline & Perceived benefits & 0.468 & 0.045 & 0.481 & 10.592 & 0.000 \\
\hline & Security risk & -0.427 & 0.045 & -0.433 & -9.584 & 0.000 \\
\hline & The group affects & 0.374 & 0.045 & 0.385 & 8.228 & 0.000 \\
\hline & Marketing Promotion & 0.205 & 0.045 & 0.213 & 4.840 & 0.000 \\
\hline & Product innovation & 0.406 & 0.045 & 0.415 & 9.067 & 0.000 \\
\hline
\end{tabular}

As can be seen from the Table 3, the absolute value of the $\mathrm{T}$ test value is greater than 4 , and for the significant coefficient of 0.000 , indicating that the corresponding standard coefficients are valid coefficients, through the $\mathrm{T}$ test. It can be seen from the table that the regression coefficients of the five factors of perceived income, safety risk, group influence, marketing promotion and product innovation are $0.468,-0.327,0.374,0.205$ and 0.406 respectively, and the coefficients are substituted into the hypothetical regression model, The final regression equation:

$$
\begin{aligned}
\text { Use intention }= & 3.802+0.468 \text { perceived benefits }-0.427 \text { security risk } \\
& +0.374 \text { group impact }+0.205 \text { marketing promotion } \\
& +0.406 \text { product innovation }
\end{aligned}
$$

In this regression analysis, the $\mathrm{F}$ value was 61.214 , and the corresponding sig- 
nificance probability Sig was 0.000 , which indicated that the regression model reached a significant level, and the adjusted $\mathrm{R} \wedge 2$ was equal to 0.662 , that is, the five influencing factors, Safety risk, group impact, marketing promotion, product innovation performance successfully explain the use of willingness to change $66.2 \%$, greater than $60 \%$, so this regression analysis of the value of the results.

\section{Conclusions}

Through the above analysis we can see that perceived benefits, group influence, marketing promotion, product innovation have a positive impact on the willingness to use, and the security risk has a negative impact on the willingness to use. At the same time, we can see that the impact of perceived benefits in the influencing factors is the greatest; the safety risk is the second; the product innovation is medium; the group influence is slightly smaller; the marketing promotion is the smallest among the five.

1) The risk and benefit are the main factors considered by the user. The higher the perceived profit of the consumer was, the higher the willingness to use was; and the lower the consumer's perception of the security risk was, the stronger the willingness to use was; and how to improve the perceived benefit and decrease User perceived risk is important to improve the willingness of users to use WeChat.

2) For the Internet industry, innovation is not only the fundamental survival and development of enterprises, but also now the pursuit of college students and young workers to stimulate, therefore, product innovation on the use of the will is also very important; the higher the user perceived product innovation is, the stronger its willingness to use will be. In addition, the community impact and marketing promotion will also have a positive role in guiding the use.

According to the above conclusions, combined with the characteristics of WeChat payment and the market environment, we put forward several suggestions as follows:

1) WeChat payment should fully collect consumer demand and preferences, and constantly expand the types of services to strengthen cooperation with banks and other financial institutions to increase the number of tied cards to give consumers more choice of space; WeChat payment can also strengthen other life services, shopping and leisure venues. The consumer can feel the convenience of WeChat payment at the same time. In addition, in the supermarket, shopping malls and hospitals, we can use WeChat to pay the user price or value-added services.

2) WeChat payment should increase the functional application, the development of innovative products, Alipay and other means of payment compared to its unique value to attract consumers to use; In addition, after marketing promotion, the need for more activities to focus on the user conversion. For the use of users, such as WeChat red envelopes can be described as "a hit", but the amount of tied cards did not translate into the actual use of the user [7].

3) To provide consumers with a safe and reliable payment platform, the in- 
troduction of security agencies, and vigorously promote security issues, reduce consumer risk and property and information security concerns, the establishment of consumer trust. In addition, through the power of social groups, to win a good reputation.

\section{References}

[1] Liu, Y. and Ye, T.Y. (2014) Research on the Factors Influencing the Adoption of Micro- credit Payment. Value Engineering, 10, 131-133.

[2] Li, Y.J. (2015) WeChat Payment Is Over-Interprete. China Electronic Commerce Research Center http://www.100ec.cn/detail--6233612.html

[3] Zeng, J. (2014) O2O Business Model Mobile Payment Intention to Use the Impact of Factors. Master's Thesis, Jinan University, Jinan.

[4] Li, X.T. (2013) Mobile Payment Consumption Use Willingness Model and Real Evidence Research. Master's Thesis, South China University of Technology, Guangzhou.

[5] Hu, L.F. (2014) Mobile Payment Platform for the Adoption of Users. Master's Thesis, Xiamen University, Xiamen.

[6] Guo, S.N. (2012) Third-Party Online Use of the Willingness to Pay and the Impact of Empirical Research-To Alipay as an Example. Master's Thesis, Nanjing University of Science and Technology, Nanjing.

[7] Ding, H. (2014) Consumer Third-Party Mobile Payment Intention to Use the Impact of Factors. Master's Thesis, Anhui University, Anhui.

\section{Scientific Research Publishing}

Submit or recommend next manuscript to SCIRP and we will provide best service for you:

Accepting pre-submission inquiries through Email, Facebook, LinkedIn, Twitter, etc. A wide selection of journals (inclusive of 9 subjects, more than 200 journals)

Providing 24-hour high-quality service

User-friendly online submission system

Fair and swift peer-review system

Efficient typesetting and proofreading procedure

Display of the result of downloads and visits, as well as the number of cited articles

Maximum dissemination of your research work

Submit your manuscript at: http://papersubmission.scirp.org/

Or contact jssm@scirp.org 